\title{
AVALIAÇÃO DO IMPACTO DO LODO DE ESGOTO NA MICROBIOTA DO SOLO UTILIZANDO O GENE 16S rRNA
}

\author{
E.A.N. Pedrinho ${ }^{*}$ E.G.M. Lemos $^{1}$ R.M. Pereira ${ }^{1}$, D.C. Scaquitto ${ }^{1}$, \\ É.L. da Silveira ${ }^{1}$, S.P. Val-Moraes ${ }^{1}$, L.M.C. Alves ${ }^{1}$, E. Wickert ${ }^{1}$, M.J. Valarini ${ }^{2}$
}

${ }^{1}$ Universidade Estadual Paulista, Faculdade de Ciências Agrárias e Veterinárias, Departamento de Tecnologia, Via de acesso Prof. Paulo Donato Castellane, s/no, CEP 14884-900, Jaboticabal, SP, Brasil. E-mail: eliamar.pedrinho@gmail.com

\section{RESUMO}

Este trabalho teve por objetivo estimar e comparar a diversidade microbiana de um solo tratado com lodo de esgoto (BAR 1N) com o mesmo solo sem tratamento (controle). A utilização do lodo de esgoto de origem industrial ou domiciliar em solos agrícolas como adubo orgânico é considerado, atualmente, uma alternativa promissora para disposição final deste resíduo. Estudos moleculares que utilizam a análise do gene 16S rRNA permitem a obtenção de informações relevantes acerca da ecologia microbiana, pois acredita-se que apenas $10 \%$ desses microorganismos podem ser cultivados. ODNA genômico dos micro-organismos presentes em ambos os solos foi extraído, clonado e, após amplificação por PCR, foi feito o sequenciamento do gene 16S rRNA. As sequências obtidas foram submetidas à análise de similaridade de nucleotídeos com o banco de dados GenBank para que pudessem ser identificadas e classificadas. Após a análise dos filogramas observou-se um número elevado de micro-organismos não identificados nos solos analisados. Os resultados demonstraram que os filos bacterianos que se destacaram foram Acidobacteria e Proteobacteria. Análises filogenéticas revelaram diferenças entre os solos, mostrando por meio de índice de diversidade bacteriana que o solo controle apresentou maior diversidade quando comparado ao solo BAR $1 \mathrm{~N}$. O filo Nitrospira revelou-se significativamente afetado pela aplicação do lodo de esgoto.

PALAVRAS-CHAVE: Biossólido, ecologia microbiana, metagenoma.

\section{ABSTRACT}

EVALUATION OF THE IMPACT OF SEWAGE SLUDGE ON SOIL MICROBES USING THE $16 \mathrm{~S}$ RRNA GENE. The objective of this work was to evaluate and compare the microbial diversity of a soil treated with sewage sludge (BAR $1 \mathrm{~N})$ with the same soil without treatment (control). The use of industrial and domestic sewer sludge as organic fertilizer in agricultural soils is currently considered a promising alternative for the final destination of these residues. Molecular studies using the analysis of the gene $16 \mathrm{~S}$ rRNA provide relevant information in regard to studies of microbial ecology, since it is believed that only $10 \%$ of these microorganisms can be cultivated. The sequences were submitted to analysis of nucleotide similarity, based on data in GenBank, in order to be identified and classified. Following phylogram analysis, a high number of nonidentified microorganisms were observed in the investigated soils. The results demonstrated that the outstanding bacterial phyla were Acidobacteria and Proteobacteria. Phylogenetic analyses revealed differences in both soils, based on the bacterial diversity index, showing that the test soil had more diversity when compared to the BAR $1 \mathrm{~N}$ soil.

KEY WORDS: Biossolid, microbial ecology, metagenomic.

\section{INTRODUÇÃO}

O uso agrícola do lodo de esgoto como adubo orgânico é considerado uma alternativa promissora para disposição final deste resíduo. Devido às suas propriedades físico-químicas, o lodo de esgoto pode ser utilizado em áreas degradadas a fim de recuperar as características necessárias para o desenvolvimen to

\footnotetext{
${ }^{2}$ Instituto de Zootecnia, Centro de Pesquisa em Genética e Reprodução Animal, Nova Odessa, SP, Brasil.
} 
da vegetação (NASCIMENTO ARAUjo, 2004), incorporação de macro e micronutrientes (BETTIOL; CAMARGO, 2006), melhoria de áreas florestadas, fertilizantes em culturas anuais de grãos e condicionador de solo (Melo et al., 2004). Por outro lado, pouco se sabe a respeito dos impactos decorrentes dessa utilização e dos seus efeitos sobre a estrutura das comunidades microbianas dos solos e sua capacidade metabólica. Processos importantes, como a ciclagem de nutrientes, estão diretamente relacionados com a atividadee diversidade microbiana do solo, existindo ainda poucos trabalhos relacionados à avaliação da diversidade de micro-organismos em solos com aplicação de lodo de esgoto.

A diversidade de micro-organismos no solo é importante para manter sua boa qualidade, já que eles desempenham inúmeras funções importantes nos solos como a participação nos ciclos do carbono, nitrogênio, fósforo (BORNEMAN, 1996), atividades metabólicas relevantes para o crescimento das plantas, recuperação de áreas degradadas (NASCIMENTO ARAUJo, 2004), decomposição de resíduos orgânicos, sequestro e desintoxicação de substâncias tóxicas (Costanza et al., 1997).

Metodologias moleculares contribuem para o desenvolvido de análise da diversidade microbiana dos solos (AMANnetal.,1995; SANDAAetal., 1998), revelando um novo cenário de distribuição dos micro-organismos em diferentes habitats(CANHOS etal., 1997; PEREIRA et al., 2006; SILVEIRA et al., 2006), inclusive dos microorganismos ainda não-cultivados em laboratório.

Este trabalho teve por objetivo analisar e comparar a diversidade genética de comunidades microbianas de um solo com aplicação de lodo de esgoto (BAR1N) com o mesmo sem a aplicação (controle) pela abordagem metagenômica.

\section{MATERIAL E MÉTODOS}

As amostras de solo foram obtidas de áreas da Empresa Brasileira de Pesquisa Agropecuária de Jaguariúna, SP, Brasil, localizada na latitude $22^{\circ} 41^{\prime}$ sul, longitude $47^{\circ} \mathrm{W}$ ealtitude de 570 meclassificadas como Latossolo Vermelho Distroférrico (textura argilosa). Coletadas em 12 pontos ao acaso $(0-20 \mathrm{~cm}$ profundidade) em zigue-zague, tanto para o solo sem tratamento (controle) como para o solo com aplicação do lodo de esgoto (BAR 1N), ambos separados por aproximadamente $500 \mathrm{~m}$ de distância. As amostras foram homogeneizadas, resultando em uma amostra composta para cada solo e foram submetidas a análises químicas e granulométricas (Tabela 1).

$\mathrm{O}$ lodo de esgoto utilizado no experimento foi obtidona Estação de Tratamento deEsgoto de Barueri, $\mathrm{SP}$, que trata esgoto domiciliar e industrial.
A extraçãodoDNA metagenômico das comunidades microbianas de cada solo, a amplificação, o sequenciamento do gene $16 \mathrm{~S}$ rRNA e a análise das sequências observadas foram realizados conforme proposto por Pereira et al. (2006) eSilveira et al.(2006). Cada sequência de DNA distinta obtida foi definida como Unidade Operacional Taxonômica (OTU). As sequências foram alinhadas pelo programa CLUSTALX v.1.81 (THOMPson et al., 1997) e submetidas à análise de agrupamento filogenético. Os filogramas foram construídos utilizando o método da distância com algoritmo "Neighbor-Joining" SAITOU; Nei(1987) e o modelo de substituição de nucleotídeos Kimura 2-P (KIMURA, 1980). As matrizes de distância foram processadas pelo programa MEGA, version 2.1 (KumAR et al., 2001) com bootstrap de 1.000 repetições. A análise da diversidade genética e diferenciação intra e interbibliotecas de sequências 16S rRNA foi realizada utilizando-se os programas Libshuff (Singleton etal., 2001), Arlequin (SChNeIDERet al.,2000) e pelo pacote "PHYLIP" (Felsentein; PhyliP, 1989). A estimativa do número das espécies foi realizada pelo programa "EstimateS" versão 6.0b1 (HiLl et al., 2002) através do estimador não paramétrico ACE ("Abundance-base Coverage Estimator").

Tabela 1 - Características químicas e granulométricas dos solos BAR $1 \mathrm{~N}$ e teste.

\begin{tabular}{lll}
\hline Características & Solo BAR 1N & Solo teste \\
\hline $\mathrm{pH}\left(\mathrm{CaCl}_{2}\right)$ & 5.2 & 5.8 \\
Matéria orgânica $\left(\mathrm{g} / \mathrm{dm}^{3}\right)$ & 27 & 25,5 \\
$\mathrm{P}\left(\mathrm{mg} / \mathrm{dm}^{3}\right)$ & 34 & 17 \\
$\mathrm{~K}\left(\mathrm{mmol}_{\mathrm{c}} / \mathrm{dm}^{3}\right)$ & 1.0 & 1.1 \\
$\mathrm{Ca}\left(\mathrm{mmol}_{\mathrm{c}} / \mathrm{dm}^{3}\right)$ & 30 & 32 \\
$\mathrm{Mg}\left(\mathrm{mmol}_{\mathrm{c}} / \mathrm{dm}^{3}\right)$ & 11 & 15 \\
$\mathrm{H}+\mathrm{AL}\left(\mathrm{mmol}_{\mathrm{c}} / \mathrm{dm}^{3}\right)$ & 38 & 28 \\
$\mathrm{SB}\left(\mathrm{mmol}_{\mathrm{c}} / \mathrm{dm}^{3}\right)$ & 42.0 & 48.1 \\
$\mathrm{~T}\left(\mathrm{mmol} / \mathrm{dm}^{3}\right)$ & 80.0 & 76.1 \\
$\mathrm{~V} \%$ & 53 & 63 \\
Argila $(\mathrm{g} / \mathrm{kg})$ & 430 & 420 \\
Limo $(\mathrm{g} / \mathrm{kg})$ & 80 & 80 \\
Areia fina $(\mathrm{g} / \mathrm{kg})$ & 170 & 180 \\
Areia grossa $(\mathrm{g} / \mathrm{kg})$ & 320 & 320 \\
Classe textural & Argilosa & Argilosa \\
\hline
\end{tabular}

\section{RESULTADOS E DISCUSSÃO}

A aplicação do lodo no solo modificou algumas propriedades químicas como $\mathrm{pH}$, que apresentou aumentodeacidez, eumaumentodefósforo(Tabela1). Isto pode ter influenciado a população microbiana nesse solo, uma vez que os filos Acidobacteria, Actinobacteria, Firmicutes, Proteobcateria edivisãoNKB19 predominaram 
nas amostras BAR-1N (solo tratado), enquanto nas amostras de solo controle (solo não tratado) apenas os filos Nitrospira e Verrucomicrobia (Tabela 2) tiveram um aumentononumerodeseusclones. Foramparcialmente sequenciados 155 clones das duas bibliotecas (BAR1N econtrole), sendo 74clones pertencentes.asamostras do solo BAR $1 \mathrm{~N}$ e 81 ao controle. As sequências obtidas apresentaram, tamanho e qualidade adequadas para a estimativa da população bacteriana, nas duas áreas conforme PEREIRA etal.(2006). Após a análisedo BLAST, foram encontradas 48 sequências distintas ou OTUs para BAR $1 \mathrm{~N}$ e 61 sequências ou OTUs para a amostra controle (Tabela 2). Todas as sequências obtidas apresentaram taxas de similaridade variando de 85 a $100 \%$ em relação ao GenBank.

O número de clones sequenciados nas duas bibliotecas revelou diversidade de bactérias pertencentes ao filo Acidobacteria. Este filo é frequentementeencontrado emamostras ambientaiscomofontes termais, ambientes marinhos, terrestres e animais quando avaliados pela análise do gene 16S rRNA (BARNs et al., 2007). HIRASHI et al. (1995) realizaram análises com este mesmo gene e propuseram que este agrupamento fosse denominado Acidobacteria, possuindoatualmentetrêsrepresentantes cultiváveis. DunBAr etal.(2002) relatarama abundância desse filo em diversos estudos de meio ambiente mostrando que ele está presente praticamente em todos habitats do mundo e em diferentes ecossistemas. Em alguns casos, representantes desse filo constituíam cerca de 30 a $50 \%$ do total da população bacteriana obtida de diferentes solos (SiLveira et al., 2006). QuAseir et al. (2003) verificaram a existência de proteínas semelhantes (PurF/PurL) entre o filo Acidobacteria e o filo Proteobacteria sugerindo uma ocorrência de transferência horizontal des ses genes entre esses filos durante a evolução, principalmente com a ordem Rhizobiales.

Dentre as 74OTUs encontradas na biblioteca BAR $1 \mathrm{~N}, 48$ foram agrupadas em 7 filos diferentes e somente 3 sequências pertencentes ao filo Divisão NKB foram observadas no solo BAR 1N (Fig. 2). Por outro lado, na biblioteca controle, 61 OTUs foram classificadas em 6 filos diferentes enenhuma sequência pertencente a esta divisão se agrupou. (Fig. 1).

Analisando a distribuição dos clones nos diferentes filos observou-se que a maioria das sequências da biblioteca BAR 1N, 37,8\% foi agrupada no filo Acidobacteria, enquanto que na biblioteca teste $35,8 \%$ agruparam-se com o mesmo filo, conforme visualizado na Tabela 2. Para o filo Firmicutes, observa-se um menor número de clones agrupados. Organismos pertencentes a esse filo apresentam baixo teor de G + C e metabolismo caracterizado por homo e heterofermentação, assim, permitem que prevaleçam em ambientes com grande quantidade de nutrientes disponíveis e áreas com baixa competição, características típicas de micro-organismos estrategistas R. Geralmente são encontrados em ambientes instáveis que estejam passando por transições(ATLAS; BARTHA, 1997).

Foram, também observadas frequências distintas de micro-organismos de alguns filos entre os solos estudados. Clones pertencentes ao filo Proteobacteria foram encontrados em maior quantidade no solo BAR $1 N$. Por outro lado, sequências agrupadas aos filos Verrucomicrobia e Nitrospira estão presente em maior número para amostra de solo controle (Tabela 2).

Dentre estes dois filos citados, o filo Nitrospira revela-se significativamente afetado pela aplicação do lodo de esgoto. Desta forma observa-se que a aplicação de lodo de esgoto em solos agrícolas é um fator de alteração da microbiota do solo, pois ele interfere no crescimento de alguns micro-organismos. Apenas uma sequência foi classificada como pertencente a esse filo em comparação com a amostra de solo controle, que apresentou dez sequências (Tabela 2). Esse filo é representado por bactérias aeróbias gramnegativas atuantes no ciclo do nitrogênio em ambientes aquáticos através da oxidação do nitrato. FAOro (2006) supõe que esse grupo pode ter atividades semelhantes no solo.

Tabela 2 - Distribuição das sequências dos clones 16S rRNA observados nos solos teste e BAR 1N.

\begin{tabular}{|c|c|c|c|c|c|c|}
\hline $\begin{array}{l}\text { Domínio: } \\
\text { bactéria filos }\end{array}$ & $\begin{array}{l}\text { BAR } 1 \mathrm{~N} \text { Nos de } \\
\text { clones distintos }\end{array}$ & $\begin{array}{l}\text { BAR 1N Nos de } \\
\text { clones observados }\end{array}$ & $\%$ & $\begin{array}{c}\text { Teste Nos de } \\
\text { clones distintos }\end{array}$ & $\begin{array}{c}\text { Teste Nos de } \\
\text { clones observados }\end{array}$ & $\%$ \\
\hline Acidobacteria & 15 & 28 & 37,8 & 19 & 29 & 35,8 \\
\hline Actinobacteria & 4 & 7 & 9,5 & 4 & 4 & 4,9 \\
\hline Firmicutes & 6 & 8 & 10,8 & 7 & 7 & 8,6 \\
\hline Nitrospira & 1 & 1 & 1,4 & 8 & 10 & 12,4 \\
\hline Proteobacteria & 13 & 18 & 24,3 & 7 & 7 & 8,6 \\
\hline Verrucomicrobia & 7 & 9 & 12,1 & 18 & 27 & 33,3 \\
\hline Divisão NKB19 & 2 & 3 & 4,0 & - & - & - \\
\hline Total & 48 & 74 & 100 & 61 & 81 & 100 \\
\hline
\end{tabular}



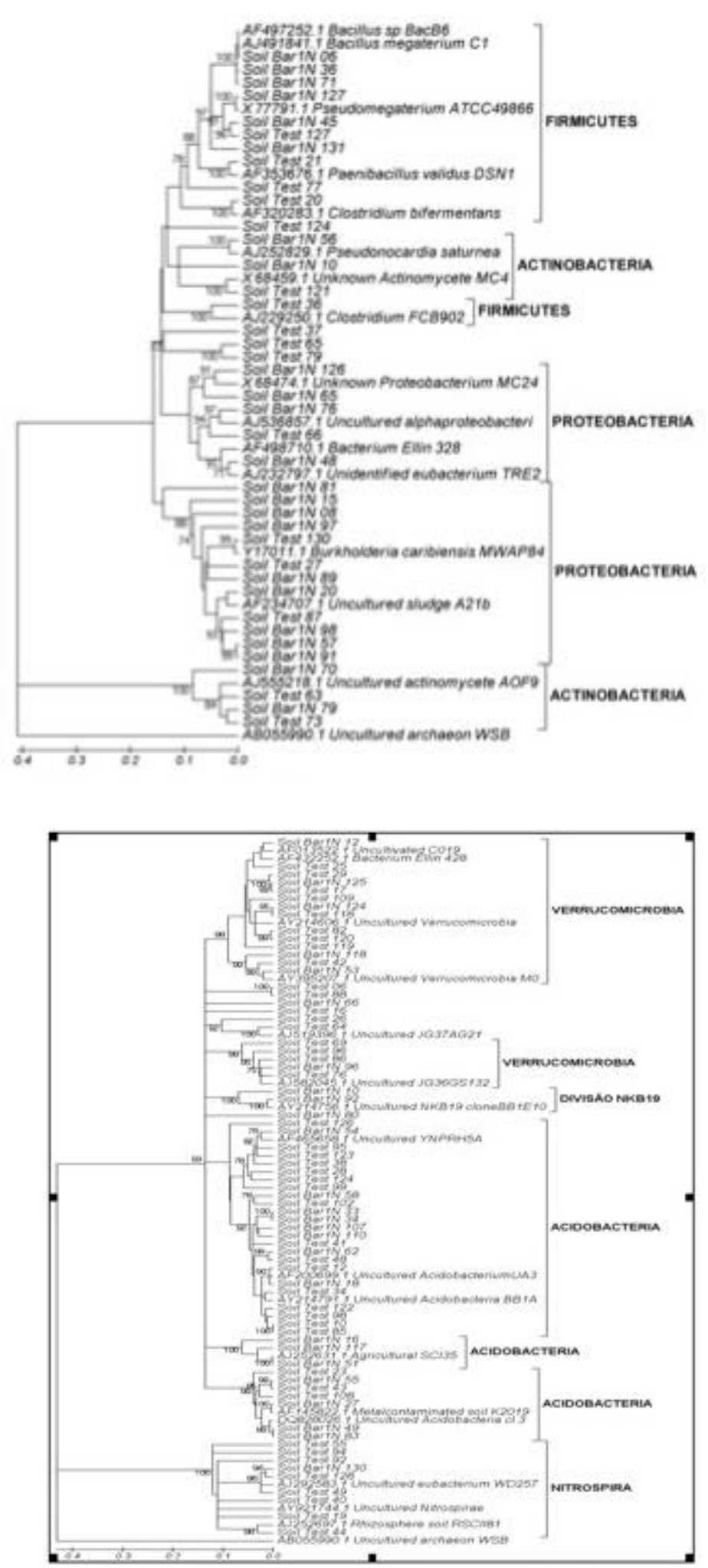

LEE (1996) relatou que o filo Verrucomicrobia representa aproximadamente de $1 \%$ a $10 \%$ das bactérias de um solo não cultivado no interior da Austrália e EUA. Os resultados obtidos no presente trabalho corroboram com os descritos por LeE (1996), na amostra de solo controle ocorreu $33,3 \%$ de represen-
Fig.1 - Dendograma filogenético representando clones pertencentes aos filos Firmicutes, Actinobactéria e Proteobactéria obtidos de sequências pareciais do gene $16 \mathrm{~S}$ rRNA de solo BAR $1 \mathrm{~N}$ e teste. A sequência $16 \mathrm{~S}$ rRNA de "Uncultures Archaeon" ( $n^{\circ}$ GenBank AB 055990) foi usado como raiz. Todos os clones estão cadastrados no NCBI (GenBank), acessados por SL (Soil BAR1N) e ST (Soil Test).

Fig.2 - Dendograma filogenético representando clones pertencentes aos filos Nitrospira, Actinobactéria, Verrucomicrobia e Divisão NKB19 obtidos de sequências pareciais do gene $16 \mathrm{~S}$ rRNA de solo BAR $1 \mathrm{~N}$ e teste. A sequência 16SrRNA de "Uncultures Archaeon" ( $\mathrm{n}^{\circ}$ GenBank AB 055990) foi usado como raiz. Todos os clones estão cadastrados no NCBI (GenBank), acessados porSL (Soil BAR1N) eST (Soil Test).

tantes desse filo, sendo que na amostra de solo BAR $1 \mathrm{~N}$ a proporção foi reduzida para $12,1 \%$, considerando assim a aplicação do lodo de esgoto como um fator de alteração da microbiota do solo. Por outro lado, foi verificado um aumento na por- 
centagem de sequências agrupadas no filo Actinobacteria, na amostra de solo BAR1N (Tabela 2). Representantes desse filo têm grande interesse econômico por produzirem substâncias complexas para degradação do material orgânico, tendo como característica a produção de diversos antibióticos. Resultados semelhantes foram encontrados por PEREIRA et al. (2006) que verificaram um aumento populacional desse filo em solo intensamente cultivado em relação a um solo coberto por floresta, provavelmente devido a alterações do meio ambiente causados pelas práticas e cultivos agrícolas.

Já a quantidade de sequências agrupadas ao filo Proteobacteria observada no solo BAR1N foi maior em relação a amostra de solo controle (Fig. 1), com valores de $24,3 \%$ e $8,6 \%$, respectivamente (Tabela 2 ). Resultados semelhantes foram obtidos por TIEDJE (1999) e SANDAA et al. (1998) que relataram o predomínio desse filo em solos de cultivo e contaminados com metal pesado que geralmente têm um $\mathrm{pH}$ mais ácido. Neste trabalho, verifica-se que o solo BAR $1 \mathrm{~N}$ apresentou maior acidez quando comparado com o solo controle, o que pode ter permitido melhor desenvolvimento de bactérias desse filo.

As análises de diversidade genética dos clones 16S rRNA heterólogos para as bibliotecas BAR 1N e teste resultaram em um valor estatisticamente significativo $(\mathrm{P} \leq 0.001)$, sendo 1,231 para teste versus BAR $1 \mathrm{~N}$ e 1,104 para BAR $1 \mathrm{~N}$ versus teste na análise realizada pelo Libshuff. Essas análises sugerem que as áreas estudadas são distintas, mas que existe uma taxa relativa de similaridade entre os solos amostrados.

$\mathrm{O}$ índice de diferenciação genética $\left(\mathrm{F}_{\mathrm{ST}}\right)$ entre as duas comunidades bacterianas (BAR $1 \mathrm{~N}$ e controle) foi significativo $\left(\mathrm{F}_{\mathrm{ST}}=0.01268\right.$, para $\left.\mathrm{P}<0.05\right)$, sugerindo que, embora o valor seja relativamente baixo, as duas comunidades são geneticamente distintas. Por outro lado, um dado interessante foi a existência de uma maior diversidade genética em cada solo individualmente do que entre as comunidades presentes BAR $1 \mathrm{~N}$ e controle, concordando com os resultados já obtidos que os filos se repetem havendo, entretanto, alteração das frequências genotípicas para os indivíduos. Os resultados da variação genética intra-populacional calculados pelo AMOVA apresentaram uma média de 98.73, ou seja, há uma grande variabilidade de organismos dentro de uma mesma comunidade, embora a maioria dos clones esteja presente em ambas as amostras dos solos.

Osoftware Arlequimanalisou sequências deDNA com 607 pares de bases de cada clone em ambos os solos calculando também a média das diferenças entre pares de bases, valores que foram de 74.35 e 88.614 para as bibliotecas lodo e controle, respectiva- mente. Já o número de nucleotídeos polimórficos, em ambos os solos, apresentou valores de 537 e 566 nas bibliotecas lodo e controle, respectivamente. Estes valores indicam a existência de uma maior diversidade genética na amostra controle em relação a BAR 1N (Tabela 2).

\section{CONCLUSÕES}

Ocorre uma diversidade bacteriana maior na amostra de solo controle em relação a BAR $1 \mathrm{~N}$ a amostra com aplicação de lodo.

Um aumento na diversidade populacional do filo Acidobacteria, Actinobacteria e Proteobacteria da biblioteca BAR $1 \mathrm{~N}$ em relação à biblioteca controle que a utilização do lodo de esgoto em práticas agrícolas é promissora, ocorrendo microrganismos com grande capacidade de decomposição da matéria orgânica.

Existe uma maior diversidade genética em cada amostra de solo individualmente, do que entre as comunidades presentes nas amostras do solo com e sem aplicação do lodo.

\section{AGRADECIMENTOS}

À Fapesp (n ${ }^{\circ}$ 03/00851-9) pelo auxílio financeiro e à Capes pela concessão de bolsa ao primeiro autor. Aos bioinformatas Maurício Egídio Cantão e Dr. Luciano Kishi pela ajuda nas análises contidas neste trabalho e à Tehuni Orlando Gonzáles pela colaboração na elaboração deste artigo.

\section{REFERÊNCIAS}

AMANN, R.I., LUDWIG, W.; SCHLEIFER, K.H. Phylogenetic identification and in situ detection of individual microbial cells without cultivation. Microbiology Review, n.59, p.143-169, 1995.

ATLAS, R.M.; BARTHA, R. Microbial evolution and biodiversity: the origins of life. In: (Ed.). Microbial ecology: fundamentals and applications. 4th. ed. Menlo Park: Book News, 1997. p.37-39.

BARS, S.M.; CAIN, E.C.; SAMMERVILLE, L.; KUSKE, C.R. Acidobacteria phylum sequences in uraniumcontaminated sediments greatly expand the known diversity within the phylum. Applied Environmental Microbiology, v.73, n.9, p.3113-3116, 2007.

BETTIOL W.; CAMARGO O.A. Lodo de esgoto: impacto ambientais na agricultura. Jaguariúna: EMBRAPA Meio Ambiente, 2006. 349p. 
BORNEMAN, J. Molcecular microbial diversity of an agricultural soil in Wisconsin. Applied and Environmental Microbiology, v.62, n.6, p.1935-1943, 1996.

CANHOS, V.P., MANFIO, G.P., VAZOLLER, R.F.; PELLIZARI, V.H. Diversidade no domínio bactéria. In: JOLY, C.A.; BICUDO, C.E.M. (Org.). Biodiversidade do Estado de São Paulo, Brasil: síntese do conhecimento ao final do século XX. 1.Microorganismos São Paulo: Fapesp, 1997. v.1, p.1-13,

COSTANZA, R.; D'ARGE, R.; DE GROOT, R.; FABER, S.; GRASSO, M.; HANNON, B.; LIMBURG, K.; NAEEM, S.; O'NEILL, R.V.; PARUELO, J.; RASKIN, R.G.; SUTTON, P.; BELT, M. van den. The value of the world's ecosystem services and natural capital. Nature, v.387, p.253-260, 1997

DUNBAR, J.; BARNS, S.M.; TICKNOR, L.O.; KUSKE, C.R. Empirical and theoretical bacterial diversity in four Arizona soils. Applied and Environmental Microbiology, v.68, n.6, p.3035-3045, 2002.

FAORO, H. Determinação da biodiversidade da Archaea e Bactéria da Mata Atlântica Paranaense. 2006. 183 p. Dissertação (Mestrado em Ciências-Bioquímica) Universidade Federal do Paraná, Curitiba, 2006.

FELSENSTEIN, J. PHYLIP: phylogeny inference package (Version 3.2). Cladistics, v.5, p.164-166, 1989.

HILL, T.C.J.; WALSH, K.A.; HARRIS, J.A.; MOFFETT, B.F. Using ecological diversity measures with bacterial communities. FEMS Microbiology Ecology, v.43, p.1-11, 2002.

HIRASHI, A.; KISHIMOTO, N.; KOSAKO, Y.; WAKAO, N.; TANO, T. Philogenetic position of the menaquinonecontaining acidophilic chemoorganotroph Acidobacterium capsulatum. FEMS Microbiology Letters, v.132, p.91-94, 1995.

KIMURA, M. A simple method for estimating evolutionary rates of base substitutions through comparative studies of nucleotide sequences. Journal of Molecular Evolution, v.16, n.2, p.111-120, 1980.

KUMAR, S.; TAMURA, K.; JAKOBSEN, I. B.; NEI, M. Mega2: molecular evolutionary genetics analysis software. Bioinformatics, v.17, p.1244-1245, 2001. LEE, S.Y. Estimation of the abundance of an uncultured soil bacterial strain by a competitive quantative PCR method. Applied and Environmental Microbiology, v.62, p.3787-3793, 1996.

MELO, V.P.; BEUTLER, A.N.; SOUZA, Z.M.; CENTURION, J.F.; MELO, W.J. Atributos físicos de Latossolos adubados durante cinco anos com biossólidos. Pesquisa Agropecuária Brasileira, v.39, n.1, p.67-72, 2004.

NASCIMENTO, C.W.A.; ARAÚJO, J.C.T. Redistribuição entre frações e teores disponíveis de zinco em solos incubados com lodo de esgoto. Revista Brasileira de Ciência do Solo, v.29, n.4, 2004.
OLIVEIRA, F.C.; MARTIAZZO, M.E.; MARCIANO, C.R.; ROSSETO,R. Efeitos de aplicações sucessivas de lodo de esgoto em um Latossolo Amarelo distrófico cultivado com cana-de açúcar, carbono orgânico, condutividade elétrica, $\mathrm{pH}$ e CTC. Revista Brasileira de Ciência do Solo, v.26, p.505-519, 2002.

PEREIRA, R.M.; DA SILVEIRA, E.L.; SCAQUITTO, D.C.; PEDRINHO, E.A.N.; VAL-MORAES, S.P.; WICKERT, E.; CARARETO-ALVES, L.M.; LEMOS, E.G.M. Molecular characterization of bacterial populations of different soils. Brazilian Journal of Microbiology, v.4, n.37, p.439-447, 2006.

QUASEIR, A; OCHSENREITER, T.; LANZ, C.; SCHUSTER, S.C.; TREUSCH, A, H.; ECK, J.; SCHLEPER,C. Acidobacteria form a coherent domain; evidence from environmental genomics, Molecular Microbiology, v.50, 563-575, 2003.

SAITOU, N.; NEI M. The neighbor-joining metod: a new method for constructing phylogenetic trees. Molecular Biology Evolution, v.4,p.406-425, 1987.

SANDAA, R.A.; ENGER, O.; TORSVIK, V. Rapid methods for fluorometric quantification of DNA in soil. Soil Biology and Biochemistry, v.30, n.2, p.265-268, 1998.

SCHNEIDER, S.D.; FURLONG, M.A.; EXCOFFIER, L. Arlequin version 2.000: a software for population genetics data analysis. Geneva: Genetics and Biometry laboratory, University of Geneva, 2000.

SILVEIRA, E.L.; PEREIRA, R.M.; SCAQUITTO, D.C.; PEDRINHO, E.A.N.; VAL-MORAES, S.P.; WICKERT, E. CARARETO-ALVES, L.M.; LEMOS, E.G.M. Bacterial diversity of soil under eucalyptus assessed by $16 S$ rDNA sequencing analysis. Pesquisa Agropecuária Brasileira, v.41, n.9, p.1507-1516, 2006.

SINGLETON, D.R.; FURLONG, M.A.; RATHBUN, S.L.; WHITMAN, W.B. Quantitative comparisons of $16 S$ rRNA gene sequence libraries from environmentalsamples. Applied and Environmental Microbiology, v.67, p. 4374-4376, 2001.

THOMPSON, J.D.; GIBSON, T.J.; PLEWNIAK, F.; JEANMOUGIN, F.; HIGGINS, D.G. The CLUSTAL_X windows interface: flexible strategies for multiple sequence alignment aided by quality analysis tools. Nucleic Acids Research, v.25, p.4876-4882, 1997.

TIEDJE, J.M.; STEIN, J.L. Microbial Biodiversity: Strategies for its recovery. In: DEMAIN, A.L.; DAVIES, J. (Ed.). Manual of Industrial Microbiology and Biotechnology. Washington, DC.: Amer. Soc. Microbiol.,1999. p.682-692.

Recebido em 15/5/08

Aceito em 19/5/09 